\title{
NOTAS SOBRE A DIMENSÃO HISTÓRICA DA CORPOREIDADE E SEU ESTUDO NO CONTEXTO DE GÊNEROS E CENAS MUSICAIS JUVENIS CONTEMPORÂNEOS: O CASO DO Pagode Baiano
}

\author{
Ledson Chagas ${ }^{1}$ \\ UFBA, Salvador-BA, Brasil
}

\begin{abstract}
Partindo de uma perspectiva dos Estudos Culturais no campo da Comunicação Massiva, este artigo busca apresentar uma articulação entre os conceitos e noções de matrizes culturais (Martin-Barbero), corporeidade (Pelinski) e repertório (Taylor), a fim de contribuir ao melhor entendimento da dimensão histórica de alguns gêneros e cenas musicais juvenis, periféricos e contemporâneos, nos quais se destaca o traço do erótico-dançante. A partir dessa articulação, o artigo aborda o caso específico das permanências e modificações performáticas no pagode baiano em relação às suas matrizes culturais. O artigo ressalta a importância de abordagens das cenas e gêneros musicais contemporâneos, dos seus sistemas de representação e das polêmicas que lhes circundam, como manifestaçôes atuais de processos de longa duração.
\end{abstract}

Palavras-chave: corporeidade, gêneros musicais, cenas musicais, pagode baiano

\section{INTRODUÇÃO}

Nos últimos 20 anos, mais ou menos, uma série de gêneros musicais tem sido amplamente difundida tanto através de mídia massiva mais consolidada, como emissoras de TV e rádio locais e nacionais, quanto através da venda de CDs e DVDs em camelôs ou, mais recentemente, em arquivos de MP3 disponibilizados em sites e redes sociais. A dimensão performática dessas produções é tão destacada que muitas das letras de suas canções são, na verdade, instruções de passos de dança, e uma grande proporção dentre elas está voltada a proporcionar diversão ao seu público através da representação de aspectos da sexualidade. Pela grande recorrência de seu uso, alguns passos e figuras se destacam nas coreografias, recebem nomes específicos, e acabam

1 Mestre pelo Programa Multidisciplinar de Pós-Graduação em Cultura e Sociedade/UFBA (2015). Graduado em Comunicação Social/Jornalismo pela UFBA (2011). Este artigo é um desdobramento de minha dissertação de mestrado, tendo a pesquisa contado com uma bolsa CAPES. E-mail: ledsonchagas@gmail.com. 
ajudando a divulgar os gêneros e suas canções dançantes, como nos casos do "pente", da "sarrada", ou da "sequência do machuca", próprios do funk carioca; do "meneaito", na cumbia villera argentina; ou do mais espetacular e envolto em polêmicas "daggering", no dancehall jamaicano. Esses diversos gêneros musicais emergem, em grande medida, de cenas musicais juvenis, ${ }^{2}$ de forte base - ainda que não exclusiva - periférica e, ainda que não se restrinjam a esse traço, têm um importante ponto em comum bem captado pelo termo erótico-dançante, proposto por Rodrigues (2012) para se referir às linguagens miméticas que geram, na interação entre pessoas nas festas populares com consumo desses gêneros, um padrão de gratificação psíquica na direção do prazer diversional (2012: 6).

Muitas questões podem ser levantadas a partir da observação dessas cenas musicais, da centralidade que a performance dançante nelas ocupa, e das polêmicas morais e políticas que as enredam. Algumas discussões tomam como foco a possibilidade de problemas associados ao consumo infantil ou, também, referentes às representações elaboradas sobre as mulheres em algumas das letras das canções. Um enfoque também importante, nesse sentido, busca captar os usos que os públicos fazem dessa produção. Ressaltando-se ainda as discussões sobre a expressão mais ampla (não restrita ao campo musical), que os agentes dessas cenas, tanto na produção quanto no consumo, acabam constituindo sobre si e sobre o grupo social no qual emergem, muitas vezes de maneira não reflexiva. Representações essas que podem abranger tanto a busca e a expressão do prazer quanto a possibilidade de reiteração (e, talvez, de subversão) de estereótipos coloniais, raciais e de classe. $\mathrm{O}$ quadro se complica ainda mais quando observamos que essa produção cultural está imersa em uma ambientação midiático-massiva, o que abrange sua estrutura, seus interesses mais consolidados, suas dinâmicas específicas (no que deve ser considerado, por exemplo, a espetacularização), bem como suas potencialidades.

Partindo de uma perspectiva dos Estudos Culturais no campo da Comunicação Massiva (sobretudo, com aportes de Jesús Martín-Barbero), este artigo tem como objeto de reflexão especificamente a dimensão performática expressa nessas cenas musicais e sua relação com repertórios performáticos de longa duração ainda do âmbito da produção musical e dançante. Um ponto de partida que nos parece ser profícuo, nesse sentido, são as noções de matrizes culturais, competências de recep̧̧ão e ritualidades, propostas pelo teórico da comunicação Jesús MartínBarbero, como integrantes de seu mapa das mediaçôes. ${ }^{3}$ Tendo como campo empírico de suas pesquisas a televisão, os gêneros televisivos e sua recepção, a noção de mediação trabalhada por Martín-Barbero, entretanto, foi proposta para e vem sendo trabalhada nos mais diversos cam-

2 A noção de cena musical está sendo utilizada aqui como proposta por Straw: "redes de interconexão social, cultural e econômica" nas quais se desempenham práticas como "comer, beber, dançar e conversar publicamente - [e que] envolvem negociação contínua sobre as relações apropriadas entre conversa e barulho, barulho e música, atenção e distração, movimento humano e as formas físicas que o englobam" (Straw 2002: 247; esta, bem como todas as seguintes traduções, são do autor deste artigo). Em uma outra definição, não restrita ao contexto musical, "as esferas circunscritas de sociabilidade, criatividade e conexão que tomam forma em torno de certos tipos de objetos culturais no transcurso da vida social desses objetos" (Straw apud Janotti Jr. 2012: 9). A grande abrangência dessa noção está indicada por ela poder dar conta tanto de fenômenos de "circulação global da música popular massiva", como o heavy metal, por exemplo, quanto de fenômenos de circulação mais restrita e referências regionalizadas (Janotti Jr. idem: 1), como é o caso de muitas das cenas musicais mencionadas neste artigo.

3 O modelo completo do mapa proposto por Martín-Barbero é o seguinte: Matrizes Culturais — institucionalidade - Lógicas de Produção - tecnicidade - Formatos Industriais — ritualidade — Competências de Recepção/Consumo - socialidade - Matrizes Culturais. Após ter trabalhado, no livro Dos Meios às Mediações (publicado originalmente em 1987), um "mapa noturno das mediações”, que consistia das mediações: cotidianidade familiar, temporalidade social e competência cultural, Martín-Barbero apresentou, em um novo prefácio para o citado livro (edição de 1998), o modelo acima mencionado. 
pos e linguagens da cultura popular-massiva, como no caso da música (Janotti Jr 2006, Leme 2003), e visa contribuir à reflexão sobre as "novas complexidades nas relações constitutivas entre comunicação, cultura e política" (Martín-Barbero 2008: 15). Mediações, como aponta o autor em referência ao campo no qual centralizou suas pesquisas, dizem respeito aos "lugares dos quais provêm as construções que delimitam e configuram a materialidade social e a expressividade cultural da televisão" (idem 294). Lopes, Borelli e Resende (2002), em pesquisa reconhecida pelo autor como a que melhor utilizou a noção (Lopes, Borelli e Resende 2002: 18), por sua vez, indicam que um ponto a ser destacado em suas conclusões é a:

Demonstração do modus operandi das mediações no processo de recepção da telenovela. Operar é o termo, porque mediações são dispositivos embutidos em práticas cotidianas e midiáticas. Isto nos permite afirmar que o grande desafio foi o de desvendar as articulações contidas, ao mesmo tempo, na narrativa da telenovela, no cotidiano e na narrativa que os receptores dela fazem" (2002: 381).

O uso da noção de mediações nesta pesquisa, dessa forma, encontra justificativa no caráter anti-fragmentário da abordagem do autor, que busca articular os diferentes eixos de seu mapa para pensar, por exemplo, as relações entre fortes traços culturais de um determinado grupo sócio-cultural (com sua inserção específica na estrutura social) e o porquê do mesmo consumir determinado produto cultural. Para pensar também, nesse sentido, as tendências, do grupo em questão, a valorar positivamente determinada produção cultural, enquanto outros grupos sócio-culturais tendem a valorá-la negativamente. Essa abordagem com foco nas interseções entre os diferentes "momentos" ou "etapas" dos processos de comunicação massiva se esforça ainda em compreender também a posição (ou a participação) de um determinado grupo social como produtor daquilo que consome, mesmo que imerso em um ambiente de negociações desenvolvidas entre seus agentes e estruturas mais amplas. Tratando-se, por exemplo, da produção de música com consumo massivo, em alguns casos essas estruturas são a indústria fonográfica de abrangência nacional (no nosso caso, brasileira), integrada a agentes multinacionais como as gravadoras majors. Em outros casos, são as cadeias de emissoras de rádio e TV locais, que, ainda assim, são espaços de poder, não sendo tão facilmente penetráveis por agentes periféricos, que negociam seu capital cultural com o capital econômico desses outros agentes. Essa abordagem, nesse sentido, dá ênfase a como a experiência de diferença cultural e de desigualdade social, que marca um determinado grupo social, se impregna nas produções que o mesmo consome (e que, em maior ou menor medida, produz ou contribui à produção). Assim, trata-se de uma perspectiva que se opõe a enfoques que caracterizam o consumo de produção cultural massiva como simples determinação de um ponto ou agentes sobre um amplo contingente humano caracterizado apenas por passividade.

Nesse sentido, Martín-Barbero ressalta a necessidade de que, no campo das pesquisas em comunicação social e nas ciências sociais com foco em produção cultural midiático-massiva, "la investigación responda a demandas de comunicación que, aunque mediadas por la industria cultural, den expresión a necesidades colectivas y recojan matrices culturales de raigambre popular" (Martín-Brabero 2002: 235).

Em seu uso mais elementar, a noção de matrizes culturais é utilizada para rastrear antecedentes históricos de gêneros ou de formas expressivas contemporâneas, por exemplo, no caso do formato industrial da telenovela, construído sobre a linguagem e sobre a experiência receptiva do radioteatro na América Latina, do cinema norte-americano, do folhetim ou novela em capítulos, remontando ao gênero teatral melodrama, do Século XIX, que possui, por sua vez, suas próprias matrizes culturais (Martín-Barbero 2008: 16 e 163-165). A noção, entretanto, busca 
dar conta também da impregnação do habitus do consumidor (idem: 164 e 170) e de marcas de sua experiência histórica na estrutura do produto, como no caso do melodrama e sua esquematização ou polarização maniqueísta dos personagens, expressando as situações-limite vividas por seu público (ibid.: 168-169), ou as reviravoltas nas relações entre os personagens membros da família do núcleo central, que expressam o peso das sociabilidades primordiais para seu grupo predominante de audiência (ibid.: $169-171$ e 306-307). ${ }^{4}$

As matrizes culturais, por sua vez, "ativam e moldam os habitus que conformam as diversas competências de recep̧cão" (ibid.: 17), que, enquanto potência, se atualizam, são postas em prática, no uso dos produtos, usos esses que, sobretudo no que diz respeito aos "produtos culturais", se dão em situações mais ou menos tipificadas, modelares, enquadramentos pragmáticos ou contextuais, nos quais os desempenhos são mediados por ritualidades, que "remete(m)-nos ao nexo simbólico que sustenta toda comunicação: à sua ancoragem na memória, aos seus ritmos e formas, seus cenários de interação e repetição" (ibid.: 19).

Reiterando o holismo do modelo de reflexão sobre os processos comunicacionais de massa proposto por Martín-Barbero, no uso dos produtos (em termos amplos), "em sua relação com os FI (formatos industriais: discursos, gêneros, programas e grades ou palimpsestos), as ritualidades constituem gramáticas da ação - do olhar, do escutar, do ler" (ibid.: 19). As diferentes competências de recepção dos diferentes grupos sociais (não exclusivamente classes ou frações de classes sociais; podendo ser também, por exemplo, grupos geracionais), por sua vez, através das ritualidades exercidas na recepção/consumo, implicam em "diferentes usos sociais dos meios" (ibid.). As ritualidades remetem também "às múltiplas trajetórias de leitura ligadas às condições sociais do gosto, marcadas por níveis de qualidade de educação, por posses e saberes constituídos na memória étnica, de classe ou de gênero, e por hábitos familiares de convivência com a cultura letrada, oral ou audiovisual" (ibid.).

Embora o modelo proposto por Martín-Barbero nos dote de uma abordagem que busca o desenvolvimento histórico dos gêneros e formatos contemporâneos (populares e massivos) e que enfoca, ainda, as constantes trocas entre consumidores e produtores, inscritas no próprio produto, sua ênfase dada ao ver, ao escutar ou ao ler, necessita como complemento, para o caso do estudo das mencionadas cenas musicais, de referenciais teóricos que dêem conta também de uma atividade como o dançar.

Para o caso das danças desenvolvidas nas cenas musicais em questão, um aspecto importante foi destacado por Fontanella (2005), quando observa, em estudo sobre a cena musical do brega pop recifense, que, "para a sua correta fruição [ou seja, para a fruição das produçôes desse gênero de acordo com suas "regras" pragmáticas], a dança deve contar com um corpo indisciplinado: é comum a menção pelos bregueiros de que para dançar o brega se necessita 'não ter vergonha' " (2005: 57; todas as observaçôes entre colchetes são minhas). Esse aspecto, da falta de vergonha quanto à expressão verbal e corporal referente à sexualidade, ao desejo sexual, e em vocabulário destoante de "normas cultas", indica, como base das produções dessas cenas musicais, um regime corporal que caracteriza, em alguma medida, o grupo social de maior participação na produção/consumo dessas cenas, e que ultrapassa esse âmbito mais autonomizado como artístico, profissional, ou posto em uso apenas em momentos de lazer, sendo constitutivo mesmo da

4 O conceito de habitus, como trabalhado por Pierre Bourdieu, foi utilizado por Martín-Barbero na elaboração das noções de competências de recep̧̧ão e matrizes culturais. 
própria formação identitária e subjetiva desse grupo. Nesse sentido, a noção de corporeidade, ${ }^{5}$ como trabalhada por Pelinski (2005), em abordagem fenomenológica, parece ser útil ao entendimento desse regime, a rigor, subjetivo: "Aunque todos los seres humanos poseen un cuerpo, no todos lo viven de la misma manera. En efecto, el cuerpo vivido es una estructura experiencial fenoménica, que funciona como nuestra consciencia subjetiva, sumergida en un mundo diferenciado por contextos históricos, socio culturales y medioambientales" (Pelinski 2005: 14). A reflexão sobre como o âmbito das práticas (evidentemente, coletivas) exerce efeito na construção das corporeidades de indivíduos, que, ainda que individuais, são compartilhadas em grupos ou moduladas coletivamente, encontra algumas bases a partir daquilo que Pelinski diz sobre a experiência musical:

Una observación más para señalar la diferencia entre corporalidad y corporeidad en el dominio de la experiencia musical: La corporalidad acoge, por de pronto, los universales acústicos del mundo físico y los biopsíquicos innatos que pueden ser procesados por el ser humano y que, por ende, condicionan sus prácticas musicales. (...) Los sonidos pertenecen al orden de la corporalidad material; la música, al orden de la corporeidad fenomênica (idem: 17-19).

[As experiências musicais, por sua vez] revisten innumerables formas, según las diferentes culturas y estilos musicales, la sensibilidad personal del músico u oyente, su edad, condición social, etc.; pueden ir desde el éxtasis de una escucha profunda hasta el canto masivo en un estadio de fútbol repleto. Todas ellas están vinculadas a modulaciones particulares de la corporeidad (ibid:: 22).

Há de se destacar, também, o papel do hábito na (constante) consolidação das corporeidades a partir das práticas: "el hábito no reside ni en el pensamiento racional ni en el cuerpo objetivo, sino en las aptitudes adquiridas a través de una práctica que sedimenta experiencias y desarrolla esquemas motrices en un cuerpo vivido preconceptualmente" (ibid.: 25). Assim, sobre as mencionadas cenas musicais e suas linguagens miméticas erótico-dançantes, podemos nos perguntar se e o quanto as mesmas são expressão de um patamar de vergonha (Elias 1993; 2011) mais característico do grupo de maior participação em sua produção/consumo, e integrante de sua modulação particular de corporeidade. Além disso, podemos nos perguntar também se e o quanto as valorações negativas que, em maior ou menor medida, e não exclusivamente, outros grupos sociais lhes aplicam, contemporaneamente, são uma extensão da perseguição a que as manifestações festivas populares e, sobretudo, com base em repertórios africanos e afro-diaspóricos, receberam das elites administrativas desde o período colonial (Tinhorão 1998; 2008; para o caso caribenho, ver Quintero-Rivera 2005).

O caso da absorção de danças camponesas pela corte, na Europa, indica o sentido no qual as manifestações festivas populares e a corporeidade que lhes dava base foram alteradas, no contexto de relações entre classes sociais naquele continente, como observa Bourdieu: "muitas dessas danças mudam de ritmo, e todas mudam de velocidade. Os movimentos amplos e rápidos tornam-se curtos e lentos. O salto torna-se passo. Deixam de ser danças destinadas a rodopiar e esquecer o mundo", deixando também de ser um divertimento para se tornar "uma cerimônia executada solenemente, a fim de excitar a admiração de um público" (Alewyn 1959: 39 apud Bourdieu 2007: 114; para o mesmo tema, ver também Burke 2013: 96-97), modificações que integram um processo mais amplo, como observa Norbert Elias (1992):

No decurso de um avanço de civilização, os movimentos tendem a ser refreados, por vezes, refinados. Em

$5 \quad$ Nas ciências socais, a noção de técnicas corporais, proposta por Mauss como "montagens fisio-psicosociológicas de séries de atos", que são "mais ou menos habituais e mais ou menos antigos na vida do indivíduo e na história da sociedade" (Mauss 2003: 420), é um antecedente da noção de corporeidade. 
sociedades que se encontram num estádio anterior de um processo de civilização, o discurso dos movimentos tende a associar-se de forma mais profunda aos movimentos dos membros ou de outras partes do corpo de uma pessoa. Num estádio posterior de um processo de civilização, gestos efusivos e que chamam a atenção são, de uma maneira geral, condenados (1992: 82).

Se essas tendências de sentido de modificação já foram registradas para o caso da inserção das danças populares europeias nas disputas culturais entre suas classes sociais, temos um indicativo do quão necessário é enquadrar as cenas musicais contemporâneas e o contexto agonístico no qual estão inseridas em uma perspectiva histórica. E é necessário fazer isso sem, por um lado, escamotear o que é observado nestas cenas, ainda quando são aspectos problematizáveis; nem, por outro, aquiescer às interpretações etnocêntricas e evolucionistas que convertem, a priori, seus traços culturais em signos de uma absoluta inferioridade, legitimando assim uma suposta superioridade moral de elites que convertem, muitas vezes, essa imagem, em meio de manutenção de seus privilégios, através de diversos e os mais espúrios métodos.

Se, em alguma medida, as produções das cenas musicais em questão, estendem uma experiência cultural mais longeva, devemos, com Taylor (2003), nos perguntar o seguinte: "O que está em risco, politicamente, ao pensarmos o conhecimento corporificado e a performance como algo tão efêmero quanto aquilo que desaparece? As memórias de quem 'desaparecem' se apenas o conhecimento de arquivo é valorizado e tem sua permanência garantida?” (Taylor 2003: 36). ${ }^{6}$ Pensando a performance como "atos vitais de transferência, transmitindo conhecimento social, memória e um senso de identidade por comportamento reiterado" (idem: 2-3), para a autora, o âmbito desses atos é tão amplo que abrange até mesmo a imaginação:

As genealogias sobre performance delineiam a ideia de movimentos expressivos como reservas mnemônicas, incluindo movimentos padronizados feitos e lembrados pelos corpos, movimentos residuais retidos implicitamente em imagens e palavras (ou nos silêncios entre elas), e movimentos imaginários idealizados nas mentes, que não são anteriores à linguagem, mas são constitutivos dela (ibid:: 5).

Essas, enfim, são algumas das linhas gerais a ser destacadas no trabalho de reflexão sobre as cenas musicais contemporâneas, enfocando a centralidade que a dança nelas ocupa, a corporeidade que caracteriza seus agentes, com seu patamar de vergonha mais ou menos específico, e as matrizes culturais que dão base às suas produções e informam as competências receptivas (e produtivas) de seu público, matrizes essas que compõem, também, um repertório de memória étnica. Tudo isso deve ser levado em conta nas reflexões sobre o agonístico contexto vivido em muitas das cidades e países latino-americanos e afro-diaspóricos (além de casos na própria África, como no do kuduro em Angola), ${ }^{7}$ em que as mencionadas cenas musicais muitas vezes são taxadas tanto como resultado de "imposição" da indústria cultural quanto como repugnante signo de primitivismo.

A seguir, abordo a problemática exposta acima a partir do caso do pagode baiano. Busco apresentar algumas de suas matrizes culturais, a partir de revisão de literatura historiográfica sobre danças populares brasileiras de matriz afro-diaspórica, e delinear algumas modificações

6 Arquivo e repertório são dois conceitos propostos pela autora para designar diferentes sistemas de armazenamento e transmissão de conhecimento e memória. O primeiro é composto de "materiais supostamente duradouros/inalteráveis (como textos, documentos, edifícios, ossos)", o segundo, "tido como efêmero, [é o] repertório de prática/conhecimento corporificado (como a língua falada, dança, esportes, ritual)” (Taylor 2003: 19).

7 Além do caso do pagode baiano, no qual venho concentrado minha pesquisa, as cenas musicais que apresentam características análogas a esta, em muitos aspectos, sobre as quais tenho lido, se concentram nesse recorte geográfico e cultural. 
e permanências performáticas (dançantes) ocorridas neste gênero musical contemporâneo, em relação às suas matrizes. Para tanto, foram selecionados alguns trechos de vídeos com exemplares desta dança, visando assim apresentar modificações ocorridas ao longo dos anos de desenvolvimento desse gênero musical, e são apresentadas também algumas informações sobre modificações musicais ocorridas durante essa trajetória, obtidas em entrevista realizada com um músico atuante no mesmo e que acompanhou a ocorrência dessas modificações. As modificações musicais conferem sentido às modificações dançantes ocorridas.

\section{O CASO dO GÊnERO Musical PAgode baiAno}

Para o pesquisador do campo da comunicação social Janotti Jr., temos, como consumidores e/ou como produtores de música, a necessidade de filtrar o excesso de informação que marca sociedades de economia capitalista e com grande produção de bens culturais, como as nossas, e daí que "tanto os campos da produção, como da circulação e do consumo desses produtos, se valem de rótulos extremamente codificados" (2006: 7), que são os gêneros. No caso dos gêneros musicais, podem ser descritos de maneira mais completa como:

gramáticas de produção do formato canção que envolvem estratégias produtivas e o sistema de recepção, os modelos e os usos que os receptores fazem desses modelos através das estratégias de leitura inscritas nos produtos midiáticos. Antes de ser um elemento imanente aos aspectos estritos da música, o gênero estaria presente no texto através de suas condições de produção e reconhecimento (idem).

Ao observarmos, com Jesús Martín-Barbero, que os gêneros musicais são "estratégias de comunicabilidade" (2008: 302), podemos perceber que essas estratégias, partindo do âmbito da produção, põem em relação: a) as práticas que realizam as intenções produtivas e econômicas de artistas e de toda uma estrutura produtiva mais ampla e voltada ao lucro e b) as competências de recepção e produtivas de um determinado grupo sócio-cultural, de onde emergem um público consumidor e produtores dotados de determinados capitais culturais. Como destaca Janotti Jr., os gêneros "envolvem regras econômicas (direcionamento e apropriações culturais), regras semióticas (estratégias de produção de sentido inscritas nos produtos musicais) e regras técnicas e formais (que envolvem a produção e a recepção musical em sentido estrito)" (Janotti Jr. 2006: 9).

O pagode baiano, portanto, é um gênero da música popular massiva, com base em todo um repertório expressivo, performático e cultural, de longo lastro histórico, mas configurado em ambientação midiático-massiva, na cidade de Salvador, no estado da Bahia, Brasil, em meados dos anos 90 (Século XX), onde suas canções dançantes, ao longo de sua trajetória, têm sido difundidas por emissoras de rádio líderes de audiência. O trabalho de grupos como Gera-Samba/ É o Tchan!, Companhia do Pagode, Terra Samba, Gang do Samba e outros, marcou uma primeira fase do gênero, em meados dos anos 90, na qual suas produções conquistaram uma difusão nacional e, em menor medida, internacional. Grande parte de seus elementos musicais, coreográficos e referentes às letras, entretanto, foram gestados em manifestações festivas populares, urbanas, em Salvador, e ainda não ou apenas parcialmente comercializadas, dos anos 80: os sambas juninos e os pagodes de mesa, cada um deles, respectivamente, apresentando um tipo de samba (música) específico: o samba corrido/samba duro (desdobramento do samba de caboclo do candomblé) e o samba ou pagode de fundo de quintal (de origem carioca) (Lima 2003: 117; Oliveira 2001: 55-66; Rodrigues 2011: 202-240). 
A partir do início dos anos 2000, a difusão nacional deste gênero - que ocorreu no contexto da difusão nacional do movimento musical mais amplo denominado axé music ${ }^{8}$ - refluiu, e o pagode baiano, aos poucos, foi se restringindo novamente, em grande medida, a uma cena musical local, dinamizada pelos shows e eventos constantes em Salvador, recorrentes em todo o estado (Bahia) e, em menor medida, realizados em outros estados. Desta segunda fase do gênero, o grupo Harmonia do Samba foi o único que manteve uma circulação nacional, com shows e exibições em programas de TV, mais próxima de como ocorria na fase inicial. Alguns grupos que lhe são contemporâneos e continuam atuando têm tido carreiras ou muito restritas à cidade de Salvador e ao restante da Bahia (Nossa Juventude, Pagod'art) ou com circulação nacional conquistada bem mais recentemente (Parangolé, Psirico).

Finalmente, por volta do final da primeira década do Século XXI, uma terceira geração de bandas, com circulação bastante circunscrita ao âmbito local, configurou novas vertentes de letras e ritmos específicos, dentro pagode baiano, e com consequências nas maneiras do público dançar: o pagofunk de grupos como Black Style/Bailão do Robyssão e La Fúria (com influências da vertente putaria do funk carioca, e pivôs das interpretações sobre e intervenções contra o machismo neste gênero musical) e o groove arrastado e seus desdobramentos, de bandas como Fantasmão/Edcity e A Bronkka/Igor Kannário, com maior ou menor absorção do rap e do discurso de grupos como Racionais $M C$ 's e outros.

Este breve apanhado tem como objetivo apenas destacar a dinamicidade da produção e da potência (maior ou menor) de circulação deste gênero musical, que está em vigor desde meados dos anos 90. Neste artigo, entretanto, o que interessa apresentar, referente ao pagode baiano, são algumas considerações sobre a maneira como sua música vem sendo dançada, ao longo dos anos, por seus artistas e público, a fim de que se possa entender melhor, a partir desse caso, como se dão as relações entre a corporeidade plasmada em danças, nestas cenas/gêneros musicais contemporâneos, e alguns repertórios culturais, sobretudo musicais e dançantes, mais longevos e que, em certa medida, contribuem à sua configuração, como matrizes culturais.

Em abordagem musicológica e semiótica, a historiadora e musicóloga Mônica Leme já apontou (partindo também da noção de matrizes culturais proposta por Martín-Barbero) a relação rítmica entre a produção da banda deflagradora do pagode baiano como gênero musical (o Gera Samba /É o Tchan!) e uma linha-guia rítmica que perpassa o lundu (que, no formato canção, data do século XVIII, mas que ainda possui precedente como lundu-dança) e o tradicional samba-de-roda do Recôncavo Baiano (Leme 2003: 70). Muitos dos elementos musicais e coreográficos apresentados na manifestação cultural dos sambas juninos, acima mencionados, por sua vez, advêm do samba-de-roda do Recôncavo Baiano, inclusive, a partir de "processos migratórios de populações do interior da Bahia em direção a Salvador, a partir dos anos 50, mas especialmente a partir dos anos 60" (Rodrigues 2011: 202), e podem ainda ser localizados nas articulações de pontos mais dispersos histórica e geograficamente, buscadas entre o lundu, o maxixe e o samba (Sodré 1998: 30) ou, em um mergulho de fôlego muito maior, entre os "batuques”, fofa, lundus, fado e samba, como apresentado por José Ramos Tinhorão, a partir das

8 Sobre a axé music, ver Moura 2001. O desenvolvimento dessa "interface de repertório musical e coreográfico”, como caracteriza o autor (Moura 2001: 215), se deu em Salvador, entre os anos 70 e 80, produção cultural essa que, entre as décadas de 80 e 90, iniciou sua difusão massiva em todo território brasileiro e, em certa medida, internacional. Artistas como Luiz Caldas, Daniela Mercury e Ivete Sangalo e bandas como o Chiclete com Banana são representativos dessa produção, ao longo de sua trajetória. 
etnocêntricas fontes da elite colonial, tão assustadas com o que, nessas manifestações culturais, lhes pareceu obsceno.

Vejamos alguns dos elementos coreográficos, apontados na abordagem historiográfica de Tinhorão (2008), que mantiveram vigência no pagode baiano ou em seus antecessores mais imediatos. Sobre uma série de danças desenvolvidas no período colonial do Brasil, pelos africanos escravizados, mas com difusão também entre mestiços livres e brancos, e já hibridizadas a "estilos de danças, formas melódicas e novo instrumental (principalmente a viola), introduzidos pelos herdeiros nativos da cultura europeia" (Tinhorão 2008: 55), o historiador destaca, além do "canto responsorial africano-crioulo", a "umbigada, simbólica das danças rituais e do lembamento (idem: 55-56)". ${ }^{9}$ Essas danças (lundu, fado e outras) tinham como singularidade o fato de já possuírem função exclusiva de proporcionar diversão (ibid.: 49), enquanto o complexo denominado "batuque", que the antecedia e dava base, configurava "uma diversidade de práticas religiosas, danças rituais e formas de lazer" (ibid.: 55). É importante destacar que tanto a umbigada quanto o canto responsorial sobrevivem ainda no samba de roda e, no caso do segundo elemento (nesse caso, não coreográfico), ainda se pode ver relação com formas em vigor no pagode baiano, como nos coros, repetidos pelos membros das bandas, dos refrões cantados pelos vocalistas.

Outro elemento coreográfico mantido em uso durante grande parte da trajetória do gênero musical pagode baiano, sobretudo pelo público (atualmente, em medida bem menor; diminuição certamente associada às modificações mais recentes pelas quais o gênero passou), é a roda, mencionada pelas fontes portuguesas coligidas por Tinhorão, que traçaram observações sobre danças rituais vistas no Congo e em Angola, no Século XIX. Alfredo de Sarmento, no livro Os Sertóes d'África: apontamentos de viagem (1880), afirma ter presenciado batuques que consistiam em um "círculo de dançadores, indo para o meio um preto ou preta que depois de executar vários passos, vai dar uma embigada, a que chamam semba, na pessoa que escolhe, a qual vai para o meio do círculo, substituí-lo" (Sarmento 1880 apud Tinhorão 2008: 59). ${ }^{10}$ Outra fonte, o comerciante português Ladislau Batalha, no livro Costumes angolenses (1890), menciona a dança do quizomba, que ocorria todas as noites, nos quintais largos, ao som da puíta (cuíca) e da cantoria dos bailarinos, com dança em roda, "dentre a qual saem uns pares que bailam no largo, dois a dois, tomando ares invocadores e posições indecorosas", com voluptuosidade e insolência (Batalha 1890 apud Tinhorão 2008: 58). A fonte complementa a descrição afirmando que "os que entram na dança cantam em côro a que os dois pares respondem em canções alusivas a todos os feitos conhecidos da vida privada dos presentes e dos ausentes" (idem).

Essas experiências coreográficas e musicais negro-africanas, com base nas características particulares do controle do próprio corpo entre seus agentes, da gestão de seus movimentos, do tipo de relação que se estabelece com as partes do corpo (por exemplo, uma não invisibilização dos genitais nos movimentos, diferentemente do direcionamento dado pelo avanço do patamar de vergonha no processo civilizatório que caracterizou o Ocidente) e dos usos e efeitos buscados por essa gestão (que pode incluir o descontrole do corpo, se necessário, para que se atinja os objetivos buscados de maneira reflexiva ou não), seja para fins de comunicação com o sagrado, para

9 O termo diz respeito ao "ajustamento do m'lemba, o preço da virgindade" (idem: 57), em cerimônias matrimoniais observadas no Congo e em Angola, no Século XIX. Ao que parece, trata-se da virgindade da noiva apenas, não do noivo.

10 Sodré (1998: 12) e o antropólogo Ordep Serra (2009: 126) destacaram que a palavra semba é a designação de umbigo no quimbundo de Angola. 
fins lúdicos, ou de excitação sexual, exerceram função de matriz cultural para danças plasmadas já na realidade colonial brasileira, e que "ficariam como expressões quase exclusivas de negros e mestiços do campo e das cidades no Brasil” (Tinhorão 2008: 85), danças essas marcadas pelo uso da umbigada, "e muito razoavelmente por isso as rodas de batuque identificadas por essa marca de semba africana passaram a ser chamadas de sambas" (idem). ${ }^{11}$

As relações coreográficas entre o pagode baiano e suas matrizes culturais se tornam bem mais perceptíveis quando recorremos a fontes contemporâneas, como na descrição que o antropólogo baiano Ordep Serra fez dos sambas de roda que ele vivenciou e observou em Festas de Largo de Salvador e em Cachoeira (desde sua infância, nos anos 40 e 50 do Século XX), samba esse que ele caracteriza como um procedimento lúdico, um folguedo, uma dança popular, uma brincadeira, que, entretanto, devido à sua polivalência, em alguns contextos, pode constituir um rito sacro (Serra 2009: 113-114). Sobre a dança no samba de roda, o autor destaca que:

Embora existam passos característicos (como o miudinho e o corta-jaca), o improviso coreográfico é indispensável, [com] simulação/dissimulação de disputa encenadas no centro de seu círculo musical. [...] Quando um homem e uma mulher dançam no centro da roda, por vezes mimam uma cópula que toma jeito de "luta amorosa": o tipo de embate em que só há vencedores. [...] é típico desta manifestação lúdica o toque jocoso. As letras das cantigas são freqüentemente cômicas, ou encerram alusões maliciosas, dichotes, gracejos; a dança costuma oscilar entre o sensual e o burlesco, que combina diversos modos (idem: 120-121).

Após descrever as sequências de passos característicos de uma modalidade mais erótica de samba de roda denominada samba de putaria, que o mesmo observou já em sua infância, o antropólogo destaca que: "o velho samba de putaria é a fonte original de inspiração de muitas das danças 'novas' (como a dança do tchan, a 'da bundinha', a 'da garrafa' e similares) criadas por grupos baianos que atualmente fazem grande sucesso" (ibid.: 124), referindo-se à primeira fase de grande difusão midiática do pagode baiano, no final dos anos 90, período em que seu livro foi originalmente publicado.

Em meu trabalho de campo, desenvolvido em casas de shows de pagode baiano, entre 2014 e 2015, observei a dança sendo feita com importantes modificações em relação a como as produções desse gênero eram dançadas em sua fase inicial. A princípio, é importante destacar que o modelo de dança mais comum no pagode baiano é formado por passos de base durante a maior parte da canção, intercalados por coreografias durante o refrão (que, em muitos casos, descreve imperativamente os movimentos da coreografia). Durante grande parte da trajetória desse gênero musical, o samba no pé era utilizado como passos de base. Nos espaços que frequentei, entretanto, pude observar que, certamente devido às mudanças musicais pelas quais esse gênero passou ao longo dos anos 2000, não é exatamente a dança do samba que predominantemente é feita, atualmente, como passos de base.

Deve-se matizar essa afirmação levando-se em conta que, com uma extensão tão grande de tempo (no mínimo, mais de dois séculos) e espaço (boa parte do território brasileiro), dificilmente as diferentes modalidades de danças denominadas samba foram dançadas sempre da mesma forma, seguindo uma única sequência de movimentos. Entretanto, a observação de vídeos de diferentes fases do pagode baiano deixa visíveis as modificações ocorridas. Em suas

11 Sodré, por outro lado, considera outras possibilidades de origem etimológica para a palavra samba, destacando que, "para o pesquisador Baptista Siqueira, o termo tem origem autóctone, pois viria do dialeto Kiriri, falado por indígenas do sertão nordestino” (Sodré 1998: 107). 
fases iniciais, ${ }^{12}$ pode-se observar que o samba no pé se fazia muito mais presente como passo de base, enquanto que, em vídeos de fases mais recentes, ${ }^{13}$ já se pode ver como passo de base uma dança mais viril, em que os ombros são muito mais exigidos, num gingado duplo, junto com o peito, ora para a direita, ora para a esquerda, alternando com os pés e pernas em sentido inverso, e em movimento muito mais saltitante do que o apresentado no samba no pé. Os braços em posição quase que "em guarda" já indicam as relações dessa maneira de dançar o pagode baiano com as posturas próprias do "pular atrás do trio", o que se relaciona, por sua vez, às modificações percussivas iniciadas, sobretudo, com a banda Psirico, e seguidas por muitas das bandas posteriores. O músico Hugo Sanbone nos traz um breve apanhado sobre essas mudanças pelas quais o pagode baiano passou, ${ }^{14}$ em meados dos anos 2000 , e como isso afetou a dança:

Márcio Victor [jovem percussionista renomado localmente, que assumiu os vocais de banda Psirico] percebeu que a música do pagode não agitava tanto o público, nos longos percursos do trio elétrico, no Carnaval, e então introduziu o andamento do galope em várias canções, mas utilizando células rítmicas subdivididas. Com o $P s i$, as coreografias já não são tão sofisticadas assim, é mais ir dançando mesmo, dentro do pulso. A substituição do tamborim e do repique pela bacurinha, tocada como solista, e o uso do torpedo e da caixa, tocando o taról junto, contribuiu muito para essas modificações. Com o passar dos anos, até o Harmonia do Samba integrou a caixa, o torpedo, assimilou a transformação.

Assim, essas modificações rítmicas introduzidas pelos músicos vão contribuindo para alterações na frequência do uso de coreografias (havendo diminuição) e nos passos de base, mudanças essas que ocorrem ao longo dos anos, gradualmente, e de difícil percepção (reflexiva) da parte público, que dança com o objetivo principal, se não exclusivo, de se divertir (geralmente, sem submeter seus movimentos a quaisquer considerações analíticas ou ortodoxias canônicas e cônscias reflexivamente).

O que dizer então sobre o argumento de Taylor de que a performance possui a capacidade de armazenar e transmitir uma memória étnica? Nessa escala micro, restrita a um gênero musical com apenas cerca de vinte anos de existência, a intenção consciente de seus agentes, de busca por diversão através do desempenho de sequências de movimentos padronizados (passos) associados - nem sempre de maneira tão consciente assim - a uma origem predominantemente africana, não é abalada pela modificação ocorrida nos passos de base. Como destaca Taylor:

O repertório mantém e transforma coreografias de significado. Entusiastas do esporte podem afirmar que o futebol se manteve sem modificação pelos últimos cem anos, mesmo assim jogadores e fãs de diferentes pa-

12 O ideal, para fazer esta comparação, seria utilizar imagens do público dançando. Como é bastante difícil encontrar vídeos que retratem bem a dança no público, ao longo da trajetória do gênero, contentemo-nos com as filmagens dos artistas. Ademais, não há por que acreditar que, ao menos quanto aos passos de base, público e artistas procedam de maneiras diferentes. Observe-se, então, sobretudo: o samba no pé dos músicos do Companhia do Pagode (trajando calça preta e colete vermelho) (https://www.youtube.com/watch?v=3ySSPNUwU-Y); o cantor, as dançarinas e o dançarino, nos trechos da canção em que a letra não descreve imperativamente os movimentos (https://www.youtube.com/watch?v=FHqup7s_jX4); trechos em que o cantor samba e imagens do público sambando (https://www.youtube.com/watch?v=sW2qiOD_YHc).

13 Ver dois trechos (02:50 a 02:58 e 07:32 a 07:44, e seguintes, ao longo do DVD), na dança do cantor (https:// www.youtube.com/watch?v=8UPd6waBgf4); ver trecho entre 00:27 a 01:00, da dança do cantor e, de maneira mais branda, dos músicos (https://www.youtube.com/watch?v=g45YrcdceFs). Acesso aos links: 23/04/2017.

14 O trombonista sergipano Hugo Santos (1978), mais conhecido como Hugo Sanbone, tocou e gravou, desde os anos 90, com muitas bandas de pagode (Oz Bambaz, Psirico, Guig Gueto, Harmonia do Samba, Miskuta, Patrulha do Samba, Dignow do Brasil) e artistas e bandas de axé (Netinho, Daniela Mercury, Ivete Sangalo, Gilmelândia, Araketu). Em 2009, criou o projeto Sanbone Pagode Orquestra, em que mescla a música erudita ocidental com a música de massa soteropolitana, sobretudo, o pagode baiano. Entrevista concedida ao autor em 24/07/2015. 
íses se apropriaram do evento de diversas maneiras. As danças mudam com o tempo, mesmo assim gerações de dançarinos (e indivíduos dançarinos) juram que elas se mantiveram iguais a antes. Mas mesmo que a base corpórea mude, entretanto, o significado pode muito bem se manter o mesmo (Taylor 2003: 20).

Mesmo em uma escala mais ampla, a pequena modificação ocorrida no passo de base do pagode baiano em nada abala sua inserção em uma linha de desenvolvimento de danças com função de diversão derivadas - em meio a hibridizações com elementos de outras procedências - dos batuques. O próprio samba no pé, apesar de seu uso ter sido diminuído como passo de base em grande parte da dança predominante atualmente neste gênero, não foi exatamente eliminado, sendo mesmo predominante, por exemplo, quando as bandas fazem seus costumeiros pout-pourris de samba de roda, ocasião na qual, inclusive, grupos no público se dispõem em rodas para acompanhar com palmas e desafiar alguém (ou uma dupla) a sambar e "quebrar" ali dentro - embora isso dificilmente ocorra em casas de show, sendo mais usual em festas de largo e nas paradas dos amplos trajetos atrás dos trios elétricos. ${ }^{15} \mathrm{O}$ passo do peneirado, do samba de roda, por exemplo, descrito por Serra como uma sequência coreográfica que "corresponde a um mimo um bocado realista do desempenho feminino em um tipo de cópula [...] em que a mulher se faz penetrar por um homem deitado ou inclinado, movendo-se sobre ele com movimentos que têm o pênis como eixo" (Serra 2009: 122), é a base daquilo que no pagode convencionou-se como "descer até embaixo", movimento ainda paradigmático da dança e, sobretudo, das coreografias convocadas nos refrões deste gênero musical contemporâneo.

Quanto a uma escala mais ampla ainda, mesmo o samba e outras danças que lhe antecederam, como já eram performadas com função de proporcionar diversão a seus dançantes e observadores, a intenção destes - e, portanto, o significado destas danças para eles - já difere dos usos religiosos, cerimoniais, que marcavam muitas das danças africanas descritas pelas fontes de Tinhorão e que ainda eram denominadas genericamente de "batuques". Uma observação de Taylor contribui ao entendimento desse tipo de modificação: "Algumas vezes, a transferência das performances ultrapassou a memória de seus significados, populações se encontrando, assim, repetindo fielmente comportamentos que eles não mais entendem” (Taylor 2003: 50).

\section{Conclusão}

Neste artigo, objetivei concatenar um referencial teórico adequado ao rastreio da dimensão histórica de elementos (mais especificamente, referentes à dança) componentes de cenas musicais contemporâneas, em grande medida periféricas, e configuradas e difundidas em ambientação midiático-massiva, já como gêneros musicais. A análise a partir do caso do pagode baiano apresenta como, num período de apenas cerca de 20 anos, a dimensão performática de um gênero musical tanto absorve inovações quanto mantém elementos mais longevos, que lhe antecedem e lhe dão base. Nesse sentido, não é uma linearidade exata que se busca entre descrições historiográficas de danças antigas e danças contemporâneas acessíveis mesmo aos nossos corpos. Nos caminhos dos "batuques" até o pagode baiano, por exemplo, se distribuem passos de danças européias, movimentos do teatro de revistas, da ginástica aeróbica, da música

15 Destacando os registros do uso desse verbo já nos contextos de danças como o lundu e o maxixe, Lima observa que, no pagode baiano, "o verbo 'quebrar' ou o uso da categoria 'nativa' 'quebradeira' diz respeito também ao requebro dos quadris, porém se refere, com mais ênfase, à movimentação erótica, enquanto se dança, de subir e descer os quadris, ou a movimentos côncavos e convexos, com os quadris, que sugerem coito sexual". (Lima 2003: 150). 
pop internacional e de outras diversas e ilocalizáveis procedências. Ainda assim, se, em alguma medida, essas cenas contemporâneas estendem repertórios que sobreviveram em circunstâncias muito adversas a si, e se o "processo de seleção, memorização ou internalização, e transmissão [de um repertório performático] ocorre em (e, por sua vez, contribui para constituir) sistemas específicos de re-presentação" (Taylor 2003: 21), devemos fortalecer a compreensão daquilo que as cenas musicais contemporâneas, enquanto manifestações atuais de processos de longa duração, podem estar expressando, no sistema de representação que elas mantêm e renovam. Bem como é necessário também buscar os significados mais amplos das polêmicas que lhes circundam.

\section{REFERÊNCIAS BIBLIOGRÁFICAS}

Bourdieu, Pierre. 2007. A economia das trocas simbólicas (organização: Sérgio Miceli). São Paulo: Perspectiva.

Burke, Peter. 2013. Cultura Popular na Idade Moderna. São Paulo: Companhia de Bolso.

Elias, Norbert. Introdução. In: Elias, Norbert \& Eric Dunning. 1992. A Busca da Excitação. Coleção Memória e Sociedade. Tradução de Maria Manuel Almeida e Silva. Lisboa: Difusão Editorial.

1993. O Processo Civilizador. Volume 2: Formação do Estado e Civilização. Rio de Janeiro: Jorge Zahar.

.2011. O Processo Civilizador. Volume 1: Uma História dos Costumes. 2a ed., Rio de Janeiro: Jorge Zahar.

Fontanella, Fernando Israel. 2005. A Estética do Brega: Cultura de Consumo e o Corpo nas Periferias do Recife - (Dissertação de Mestrado) Programa de Pós-Graduação em Comunicação, Universidade Federal de Pernambuco.

Janotti Jr, Jeder. 2006. "Por uma análise midiática da música popular massiva. Uma proposição metodológica para a compreensão do entorno comunicacional, das condições de produção e reconhecimento dos gêneros musicais”. E-Compós, 1(6): 1-15. Disponível em: http:// compos.org.br/seer/index.php/e-compos/article/viewFile/84/84 Acesso: 23/04/2017.

2012. "Entrevista - Will Straw e a importância da ideia de cenas musicais nos estudos de música e comunicação". E-Compós, 2(15): 1-10. Disponível em: http://www.compos. org.br/seer/index.php/e-compos/article/view/812. Acesso: 23/04/2017.

Leme, Mônica Neves. 2003. Que Tchan é Esse? Indústria Cultural e Produção Musical no Brasil dos Anos 90. São Paulo: Annablume.

Lima, Ari. 2003. A Experiência do Samba na Babia - Práticas corporais, raça e masculinidade(Tese de Doutorado) Programa de Pós-Graduação em Antropologia Social, Universidade de Brasília.

Lopes, Maria Immacolata Vassalo de; Borelli, Sílvia Helena Simões; Resende, Vera da Rocha. 2002. Vivendo com a Telenovela: mediações, recepção, teleficcionalidade. São Paulo: Summus Editorial.

Martín-Barbero, Jesús. 2002. Ofício de Cartógrafo: Travesías latinoamericanas de la comunicación en la cultura. Santiago, Chile: Fondo de Cultura Económica. 2008. Dos meios às mediações: comunicação, cultura e hegemonia. 5a ed. Rio de Janeiro: Editora UFRJ.

Mauss, Marcel. 2003. Sociologia e Antropologia. São Paulo: CosacNaify. 
Moura, Milton. 2001. Carnaval e Baianidade. Arestas e curvas na coreografia de identidades do carnaval de Salvador - (Tese de Doutorado) Programa de Pós-Graduação em Comunicação e Cultura Contemporâneas, Universidade Federal da Bahia.

Oliveira, Sirleide. 2001. O pagode em Salvador: produção e consumo nos anos noventa - (Dissertação de Mestrado) Programa de Pós-Graduação em Ciências Sociais, Universidade Federal da Bahia.

Pelinski, Ramón. 2005. "Corporeidad y experiencia musical." Trans. Revista Transcultural de Música, 1(9). Disponível em: http://www.sibetrans.com/trans/articulo/177/corporeidad-y-experiencia-musical. Acesso: 23/04/2017

Quintero-Rivera, Angel. 2005. "The somatology of manners: class, race and gender in the history of dance etiquette in the Hispanic Caribbean." Pp. 152-181 em Ethnicity in the Caribbean: Essays in Honor of Harry Hoetink, editado por G. Oostindie. Amsterdam: Amsterdam University Press-Amsterdam Academic Archive.

Rodrigues, Fernando de Jesus. 2011. Economia Simbólica da Excitação: sobre os circuitos musicais populares nas periferias e o sentido erótico-dançante no tecnobrega e no pagode baiano-(Tese de Doutorado) Departamento de Sociologia, Universidade de Brasília.

2012. "Aspectos da estrutura de poder entre homens e mulheres e as diversões erótico-dançantes no Brasil contemporâneo." Anais do XIV Simpósio Internacional Processos Civilizadores: civilidade, fronteira, diversidade: 1-15 Disponível em: http://www.uel. br/grupo-estudo/processoscivilizadores/portugues/sitesanais/anais14/arquivos/textos/ Workshop/Trabalhos_Completos/Fernando_Rodrigues.pdf Acesso: 23/04/2017.

Serra, Ordep. 2009. Rumores de festa. O sagrado e o profano na Babia. Salvador: Editora EDUFBA. Sodré, Muniz. 1998. Samba, o dono do corpo. 2a ed. Rio de Janeiro: Mauad.

Straw,Will.2002. "Scenes and Sensibilities.” Public,(22/23):245-257. Disponível em: http://public.journals.yorku.ca/index.php/public/article/view/30335/27864. Acesso: 23/04/2017.

Taylor, Diana. 2003. The Archive and the Repertoire: Performing Cultural Memory in the Americas. Durham: Duke University Press.

Tinhorão, José Ramos. 1998. História Social da Música Popular Brasileira. São Paulo: Editora 34. 2008. Os sons dos negros no Brasil. cantos, danças, folguedos: origens. 2a ed., São Paulo: Editora 34.

\section{NOTES ON THE HISTORICAL DIMENSION OF EMBODIMENT AND ITS STUDY IN THE CONTEXT OF CONTEMPORARY YOUTH MUSIC GENRES AND SCENES: THE CASE OF Pagode Baiano}

From a Cultural Studies' perspective within the field of mass communication, this article aims to bring together the concepts of cultural matrix (Martin-Barbero), embodiment (Pelinski) and repertoire (Taylor), in order to contribute to the better understanding of the historical dimensions of some contemporary "ghetto" youth music genres and scenes, in which the erotic-dancing traits are relevant. From this perspective, the article addresses the specific case of the permanence and modifications in the performance of Pagode Baiano in relation to its cultural matrices. The article emphasizes the impor- 
tance of analyzing contemporary music genres, their representational systems and the controversies that surround them, as manifestations of long-term processes.

Keywords: embodiment, music genres, music scenes, pagode baiano

Recebido em: 2017-05-31

Aceitado em: 2018-02-24 